\title{
A HIGH-CHARGE-STATE ACCELERATION SCHEME FOR POTENTIAL UPGRADE OF THE HRIBF
}

\author{
Y. Zhang,* G. D. Alton \\ Physics Division, Oak Ridge National Laboratory, Oak Ridge, TN 37831-6368, USA
}

\begin{abstract}
This article describes a high-charge-state linear post accelerator for enhancing the number and intensities of short-lived radioactive nuclei at the Holifield Radioactive Ion Beam facility (HRIBF). The system consists of a room temperature RFQ, a normal conducting IH linac and a SC QWR linac that is designed to either bypass or post accelerate beams from the 25-MV tandem. The voltage gain of the linac system will reach $60 \mathrm{MV}$ making possible the acceleration of ions with masses, $M \leq 150$, above the Coulomb barrier. Since the linac accelerates positive-ion beams, it will increase the number of elements that can be delivered for research by a factor of $\sim 3$ and the intensity of a given species by orders of magnitude over those of the present HRIBF.
\end{abstract}

\section{INTRODUCTION}

The Holifield Radioactive Ion Beam Facility [1], completed in 1997, is the first ISOL-based RIB facility in America. It consists of the following major components: the $\mathrm{k}=100$ Oak Ridge Isochronous Cyclotron, an IsotopeSeparator-On-Line and the 25-MV URC tandem accelerator. Although the tandem is a highly reliable postaccelerator, the species are limited to those that can be efficiently produced in negative ion form, either directly or indirectly. Since the majority of the elements have electron affinities less than $1 \mathrm{eV}$, most beams must be generated by charge exchange. The process degrades RIBs by inducing energy spreads of a few hundred $\mathrm{eV}$ during collisions with the exchange vapor, and therefore, compromises the ability to remove isobaric contaminants with conventional magnetic systems. Although the ORIC, built in 1962, has a $\mathrm{k}=100$ rating, in practice, it operates at $\mathrm{k} \cong 42$ for proton beams because of RF tuning and radial focusing limitations. Thus, production of short-lived species is greatly restricted because of the limited intensities and energies available with ORIC beams. The high-intensity linac driver, designed as a replacement for the ORIC, can accelerate proton beams to $200 \mathrm{MeV}$ with intensities up to $200 \mu \mathrm{A}$, corresponding to a beam power of $\sim 2$ orders of magnitude higher than those from the ORIC. LNL has chosen a positive-ion injector [2] and ANL has proposed a next generation RIB facility, RIA [3] based on the acceleration and fragmentation of high-energy heavy-ion beams.

As discussed previously, the 25-MV URC tandem accelerator limits the number and intensities of most RIB species because of the necessity of having to inject negative-ion beams, most of which must be formed through charge exchange of initially positive-ion beams. The charge-exchange process, not only compromises beam quality, but also reduces the efficiency of RIB generation. For a typical case for which the efficiency for both positive- and negative-ion formation is $10 \%$, the overall efficiency is reduced to $1 \%$. RIB beam intensities are further reduced by the use of gas or C-foil strippers in the terminal of the tandem, resulting in transmission losses. (The transmission efficiency for a gas stripper is $\sim 20 \%$ while that of a $\mathrm{C}$-foil stripper is $\sim 8 \%$, in the $25-\mathrm{MV}$ tandem.) Thus, for the example cited, the RIB intensity for the gas stripping scenario would be reduced to $0.2 \%$ and to $\sim 0.08 \%$ for a $\mathrm{C}$-foil stripper. The proposed high-chargestate linac system is predicated on the use of a multicharge-state ECR ion source that can generate beams of noble gas elements such as ${ }^{40} \mathrm{Ar}^{9+}$ and ${ }^{84} \mathrm{Kr}^{14+}$ and volatile metals such as $\operatorname{In}^{20+}$ at $>10 \%$ efficiency. Thus, the efficiencies for the high-charge-state linac system would be amplified by factors, of $\sim 125$ and $\sim 50$ over those for the existing tandem accelerator based HRIBF system. In the advent that the charge-state breeding concept $\left(\mathrm{A}^{1+} \rightarrow \mathrm{A}^{\mathrm{q}+}\right)$ must be utilized in order to protect radiation sensitive permanent magnets in ECR ion sources from degradation, the overall efficiency would decrease to $\sim 1 \%$ for the high-charge-state acceleration scheme. Thus, the efficiency would still be 12.5 to 5 times higher than either of the tandem stripper scenarios. (The breeder method is being developed for use at high-charge-state accelerator RIB facilities such as SPIRAL at GANIL [4].)

A description of the high-intensity light-ion linear driver accelerator can be found in a technology report [5], and will not be included in this paper. In the conceptual design studies for the linear accelerator, the codes, TRACE3D [6], LYRAN [7], PARMILA [8], and the electromagnet code SUPERFISH [9] were used to design components of the high charge-state linac system and RFQ codes such as PARMTEQ [10] were used to simulate transport through the RFQ. A low-charge-state heavy-ion linear accelerator system, designed as an alternate candidate system for upgrading the HRIBF, is also described in these proceedings [11].

\section{SCOPE OF THE LINAC}

Fig. 1 schematically represents the proposed highcharge-state linac system while the elements of the system and their performance parameters are listed in Table 1. In addition to the high-intensity linac driver, the energy booster for the HRIBF will consist of a high-charge-state ECR ion source, a normal conducting RFQ, four NC Inter-

\footnotetext{
${ }^{*}$ China Institute of Atomic Energy, Beijing, China.
} 
Digital H type resonators (IH cavities) and a SC QWR linac system. RIBs from the ECR ion source are passed through a first stage $\mathrm{M} / \mathrm{q}$ analyzer, accelerated from the high voltage platform through an isobar separator (mass resolution: $M / \Delta M=20000$ ) before injection into the 100 $\mathrm{MHz}$ NC RFQ. Normal conducting IH cavities are chosen as the acceleration structures between the RFQ and the SC QWR linac, since they have very high acceleration efficiencies in the output velocity range of the RFQ, $(0.02 \geq \beta \geq 0.05)$. The combined voltage gain of the room temperature components of the post accelerator system (i.e., ECR, RFQ, and $\mathrm{IH}$ linac) is $7.5 \mathrm{MV}$. The output energies for heavy ions from the room temperature system are equivalent to those from a $13 \mathrm{MV}$ tandem.
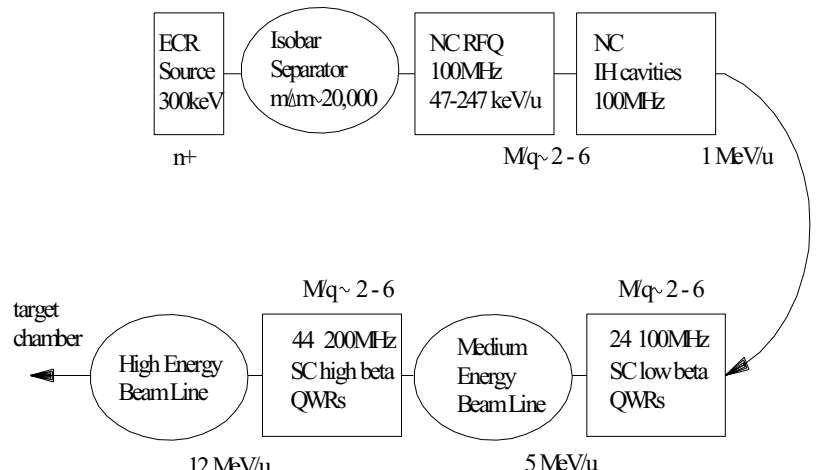

Fig. 1. Schematic diagram for acceleration of high-chargestate RIBs.

The SC linac booster is the best choice for accelerating RIBs to their final energies because SC cavities operate reliably at high field gradients in $\mathrm{CW}$ mode at reduced cost. In addition, the independently phased Quarter-Wave-Resonators have a very broad velocity profile so that the energies of RIBs can be varied over a wide range. The normal conducting RFQ, NC IH linac, and low beta SC linac sections, operate at $100 \mathrm{MHz}$ and have a combined voltage gain of $\sim 25 \mathrm{MV}$. The high beta SC QWR linac section operates at a resonant frequency of $200 \mathrm{MHz}$ and has a voltage gain of $\sim 35 \mathrm{MV}$.

Table 1. Acceleration elements of the new HRIBF

\begin{tabular}{|l|ccccc|}
\hline Element & $\begin{array}{c}\text { Beta } \\
(\mathrm{v} / \mathrm{c})\end{array}$ & $\begin{array}{c}\mathrm{F} \\
(\mathrm{MHz})\end{array}$ & Num. & Type & $\begin{array}{c}\text { Gain } \\
(\mathrm{MV})\end{array}$ \\
\hline ECR & $0-0.009$ & & 1 & $\mathrm{NC}$ & 0.3 \\
RFQ & -0.023 & 100 & 1 & $\mathrm{NC}$ & 1.2 \\
IH & -0.051 & 100 & 4 & $\mathrm{NC}$ & 6 \\
QWR & $-0.104^{*}$ & 100 & 24 & $\mathrm{SC}$ & 18 \\
QWR & $-0.160^{*}$ & 200 & 44 & $\mathrm{SC}$ & 35 \\
\hline \multicolumn{7}{c}{ *Mass-to-charge ratio about 5 }
\end{tabular}

\section{NORMAL CONDUCTING RFQ}

The charge-to-mass ratio is a key parameter for the design of a heavy-ion RFQ. The high-charge-state ECR ion source [12] is assumed to produce beams with massto-charge, (M/q) ratios within the range of 2 to 6 . Since the injector has a maximum voltage of $300 \mathrm{kV}$, the RFQ is designed to accept beams with energies of $\sim 46.7 \mathrm{keV} / \mathrm{u}$ and to accelerate them to an output energy of $\sim 247 \mathrm{keV} / \mathrm{u}$.
The normal conducting RFQ has a voltage gain of $1.2 \mathrm{MV}$ and serves mainly as an adiabatic beam buncher that captures, focuses, and accelerates $\sim 90 \%$ of injected DC beams. Since intensity is at a premium at any RIB facility, the high bunching efficiency attribute of the RFQ is an added bonus of the heavy-ion linac post-accelerator concept.

Table 2. Design parameters of the RFQ

\begin{tabular}{|l|l|}
\hline Frequency & $100 \mathrm{MHz}$ \\
\hline Number of cells & 193 \\
Vane length & $377 \mathrm{~cm}$ \\
Minimum aperture radius & $3.0 \mathrm{~mm}$ \\
\hline Peak vane voltage & $78 \mathrm{kV}$ \\
Peak surface electric field & $2.0 \mathrm{Ek}$ \\
RF power & $62 \mathrm{~kW}$ \\
Input beam & $46.7 \mathrm{keV} / \mathrm{u}(\beta=0.010)$ \\
Output beam & $247 \mathrm{keV} / \mathrm{u}(\beta=0.023)$ \\
\hline
\end{tabular}

The RFQ operates at a resonant frequency of 100 $\mathrm{MHz}$ and has a normalized transverse acceptance of $\sim 1.0$ $\pi \cdot \mathrm{mm} \cdot \mathrm{mrad}$. It is housed in a cavity of length: $\sim 4 \mathrm{~m}$, and inner diameter: $\sim 45 \mathrm{~cm}$. For practical $\mathrm{CW}$ operation, the maximum inter-vane voltage will be $78 \mathrm{kV}$, and the RF power dissipated on the entire RFQ structure, $\sim 60 \mathrm{~kW}$. The apertures in the last four cells of the RFQ will be increased to reduce radial focusing and lower the maximum magnetic gradient as required to optimally match into the following IH cavities and quadruple structures. The design parameters of the RFQ are listed in Table 2, while Fig. 2 shows the beam transport results obtained with PARMTEQ.

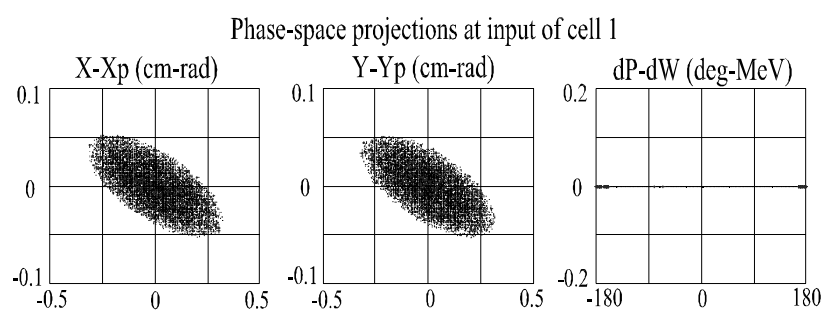

Phase-space projections at output of cell 193
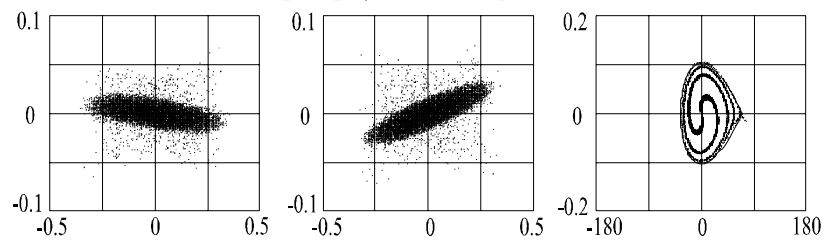

Fig. 2: Phase-space projections of beams injected into and exiting from the RFQ.

\section{NC IH CAVITIES}

Room temperature Inter-digital $\mathrm{H}$ type resonators ( $\mathrm{IH}$ cavities) were chosen for acceleration of beams from the RFQ because of their high acceleration efficiencies [13, 14] in the velocity range, $0.02 \geq \beta \geq 0.05$. Four $100 \mathrm{MHz}$ $\mathrm{IH}$ cavity tanks are required to accelerate ions for injection into the super-conducting QWR linac. These structures are practical for $\mathrm{CW}$ operation since the RF power dissipated 
in the walls of each IH tank is less than $20 \mathrm{~kW}$. The four tanks are independently phased and beams from the RFQ can be efficiently captured, accelerated, and injected into the following SC linac. The design parameters for the $\mathrm{IH}$ cavities are: injection velocity, $\beta=0.023$; output velocity, $\beta=0.051$; voltage gain, $6 \mathrm{MV}$; total electrode length, $\sim 3 \mathrm{~m}$; tank diameter, $\sim 70 \mathrm{~cm}$. Since the inter-tank distances need to be short in order to reduce longitudinal mismatching, magnetic quadruple doublet lenses with high gradients will be installed between each IH tank to provide strong transverse focusing; this distance can be made as short as $30 \mathrm{~cm}$. Fig. 3 displays the results of simulation studies obtained by use of the TRACE3D.
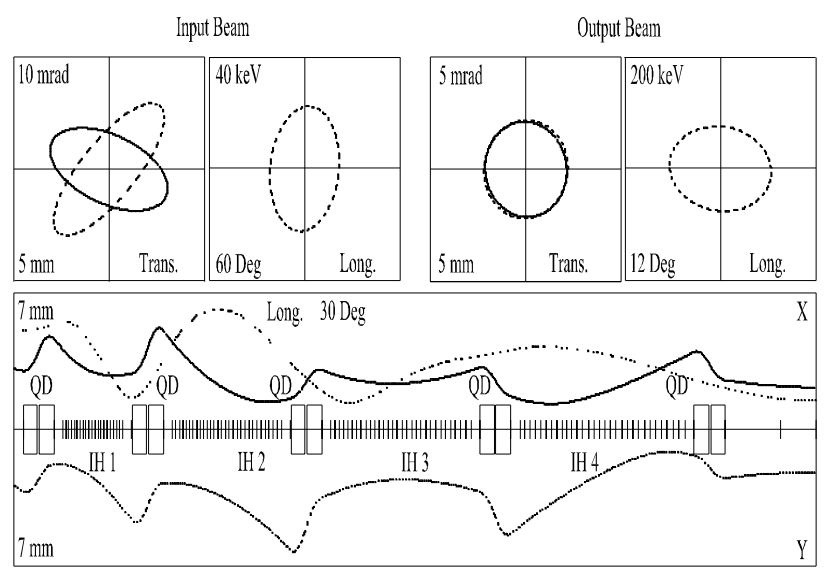

Fig. 3: Beam envelope through the IH linac

\section{SC LINAC PERFORMANCE}

Acceleration and transport of heavy ions in the post accelerator are simulated with several codes introduced previously and details of the SC linac described in Ref. 11. These studies show that the new linac system is capable of accelerating intermediate mass ions such as $\mathrm{M} \cong 85$ to 12 $\mathrm{MeV} / \mathrm{u}$, assuming a M/q ratio of 5 and heavy ions with $\mathrm{M}$ $\leq 150$ to $10 \mathrm{MeV} / \mathrm{u}$ that have $\mathrm{M} / \mathrm{q}$ ratios of 6 . Simulation results of the SC linac are listed in Table 3.

Table 3. Beam simulation results

\begin{tabular}{|c|c|c|c|c|c|c|}
\hline Ion & $\mathrm{O}^{+8}$ & $\mathrm{Ar}^{+13}$ & $\mathrm{Ni}^{+15}$ & $\mathrm{Ge}_{5}^{+1}$ & $\mathrm{Kr}^{+17}$ & $\underset{7}{\mathrm{Xe}^{+2}}$ \\
\hline & 19.2 & 47.9 & 70.3 & 88.6 & 100 & 158 \\
\hline $\mathrm{MeV} / \mathrm{u}$ & 1.2 & 1.2 & 1.2 & 1.2 & 1.2 & 1.2 \\
\hline \multirow{4}{*}{$\begin{array}{l}\beta_{\text {mid }}{ }^{*} \\
\mathrm{E}_{\text {mid }}{ }^{*} \\
\mathrm{MeV} / \mathrm{q}\end{array}$} & 0.14 & 0.12 & 0.11 & 0.10 & 0.10 & 0.10 \\
\hline & 1 & 1 & 2 & 4 & 3 & 1 \\
\hline & 149 & 276 & 343 & 368 & 419 & 635 \\
\hline & 19 & 21 & 23 & 25 & 25 & 24 \\
\hline \multirow[t]{2}{*}{$\beta_{\text {out }}$} & 0.23 & 0.19 & 0.17 & 0.16 & 0.16 & 0.15 \\
\hline & 2 & 6 & 7 & 1 & 0 & 9 \\
\hline$E_{\text {out }}$ & 417 & 745 & 879 & 900 & 1021 & 1592 \\
\hline $\mathrm{MeV} / \mathrm{u}$ & 26.0 & 18.4 & 14.9 & 12.2 & 12.2 & 12.0 \\
\hline $\mathrm{MeV} / \mathrm{q}$ & 52.1 & 56.5 & 58.6 & 60.0 & 60.1 & 59.0 \\
\hline
\end{tabular}

\section{CONCLUSIONS}

According to the conceptual design studies described in this report, the high-charge-state post-acceleration system and combination of the $200-\mathrm{MeV}$ high intensity proton linear driver accelerator will significantly enhance the research capabilities of the HRIBF. The system can optimally accelerate ions with mass-to-charge ratios, $\mathrm{M} / \mathrm{q}=5$ or 6 to energies up to $\sim 60 \mathrm{MeVq}$. The modular aspects of the design make construction of the project in stages very appealing whenever budgetary restrictions preclude construction of the full energy complement. However, if the project is divided into stages, the room temperature components (ECR ion source, RFQ and the 4tank NC-IH system) should be built as an integral standalone acceleration system since this combination has a voltage gain sufficiently high ( $\sim \mathrm{MV})$ to perform nuclear astrophysics research $(\mathrm{E} \geq 1 \mathrm{MeV} / \mathrm{u})$ with species up to mass, $M=150$. Studies directed toward further optimization of the HRIBF upgrade acceleration system in terms of simplicity, efficiency, ease of operation and cost of the facility continue.

\section{ACKNOWLEDGEMENTS}

Research sponsored by Oak Ridge National Laboratory, managed by UT-Battelle, LLC, for the U.S. Department of Energy under contract number DE-AC0500OR22725. The authors would like to thank Dr. V. Palmieri and Dr. A. Porcellato of LNL, Dr. S. Takeuchi of JAERI, and Prof. W. Jiang of CIAE for providing information.

\section{REFERENCES}

1. G. D. Alton and J. R. Beene, J. Phys. G: Nucl. Part. Phys. 24 (1998) 1347.

2. A. Lombardi, G. Bassato, A. Battistella, et al., The New Positive Ion Injector PIAVE at LNL, Proc. '97 Particle Accelerator Conference, 1997.

3. K. W. Shepard, J. R. Delayen, C. M. Lyneis, et al., SC Driver Linac for a Rare Isotope Facility, Proc. $9^{\text {th }}$ Workshop RF Superconductivity, 1999.

4. W. Mittig, J. Phys. G. Nucl. Part. Phys. 24 (1998) 1331.

5. Concept Design Study for the HRIBF Driver Linac, final report to ORNL, ACCSYS Technology Inc., July 1997.

6. TRACE3D, linear accelerator code from LANL.

7. LYRAN is a computer code for linear accelerators with independently phased resonators, first written by A. Scholldorf at Stony Brook.

8. PARMILA, linear accelerator code, from LANL.

9. SUPERFISH, 2D electromagnet code, LANL.

10. K. R. Crandall, T. P. Wangler, L. M. Young, et al., RFQ Design Codes, LANL, 1998.

11. Y. Zhang, G. Alton, "Low Charge State Rib Acceleration Scheme for Potential Upgrade of the HRIBF", these proceedings, PAC 2001.

12. Z. Q. Xie, Rev. of Sci. Instr. 69 (1998) 625.

13. M. Tomizawa, S. Arai, Y. Arakaki, et al., Progress Report of the Interdigital-H Linac for Radioactive Nuclei Ins, Proc. of Linac'96.

14. B. Krietenstein, T. Weiland, U. Ratzinger, et al., Numerical Simulation of IH-accelerators with MAFIA and RF Model Measurements, Proc. of Linac'96. 